\title{
TREATMENT OF WASTEWATER AND ELECTRICITY GENERATION USING MICROBIAL FUEL CELL TECHNOLOGY
}

\author{
B.G. Mahendra ${ }^{1}$, Shridhar Mahavarkar ${ }^{2}$ \\ ${ }^{1}$ Associate Professor, ${ }^{2}$ M.Tech Scholar, Department of Civil Engineering, Poojya Doddappa Appa College of \\ Engineering, Gulbarga-585102, Karnataka \\ bgm_pda@yahoo.co.in, shridhar_m21@yahoo.co.in
}

\begin{abstract}
The need for alternate eco-friendly fuel is increasing rapidly with the depletion of non-renewable energy resources. Microbial fuel cells (MFCs) represent a new form of renewable energy, which converts organic matter into electricity with the help of bacteria present in wastewater, while simultaneously treating the wastewater. In the present study single chamber (MFC-1) and double chambered (MFC-2) MFCs were compared for domestic and dairy wastewater treatment and electricity generation. MFC-1 was proved to be more efficient and found to be producing maximum current of $0.84 \mathrm{~mA}$ and $1.02 \mathrm{~mA}$ whereas MFC-2 produced maximum current of $0.56 \mathrm{~mA}$ and $0.58 \mathrm{~mA}$ from full strength (100\%) domestic and dairy wastewater concentrations respectively. COD removal efficiency achieved in MFC-2 was $88.4 \%$ and $86.42 \%$ for $100 \%$ domestic and dairy wastewater concentrations respectively when compared with MFC-1 which attained $86.6 \%$ and $84.8 \%$ respectively for $100 \%$ domestic and dairy wastewater concentrations respectively. The performance of MFC-1 and MFC-2 decreased, when the wastewater concentration was decreased from $100 \%$ to $75 \%$ and $50 \%$ concentrations.
\end{abstract}

Keywords: Microbial Fuel cell, bioelectricity, wastewater, salt bridge, air cathode.

\section{INTRODUCTION}

Increasing human activities are consuming the natural energy sources leading to the depletion of fossil fuels. The presentday energy scenario in India and around the globe is precarious. The need for alternate fuel has made us to initiate extensive research in identifying a potential, cheap and renewable source for energy production. The building of the sustainable society will require reduction of dependency on fossil fuels and lowering the amount of pollution that is generated [1]. Current methods to produce energy are not sustainable, and concerns about climate and global warming require developing new methods of energy production using renewable and carbon-neutral sources [2].

Microbial Fuel cell (MFC) is a device designed for the purpose of electricity generation in the process of wastewater treatment. Hence it is an ideal solution for sustainable non renewable source of energy. MFC can be defined as electrochemical devices that convert the chemical energy contained in organic matter into electricity by means of catalytic (metabolic) activity of the living microorganisms [35]. MFCs have gained significance in the last few decades due to their capability to produce energy, either as electricity or through hydrogen production, from renewable sources such as sewage waste and other similar waste sources. The MFC consists of anode and cathode separated by a proton exchange membrane or a salt bridge. In the anode chamber, the substrate is oxidized by microorganisms generating protons and electrons. The electrons are transferred through an external circuit, while the protons diffuse through the solution to the cathode, where electrons combine with protons and oxygen to form water. There are two kinds of microbial fuel cells: mediator and mediator-less. In mediator microbial fuel cell, the bacteria are electrochemically inactive. The bacteria digest the organic matter and create electrons. The electron transfer from microbial cells to the electrode is facilitated by mediators such as thionine, methyl blue, methyl viologen, humic acid, neutral red and so on[6-7]. Most of the mediators available are expensive and toxic to bacteria. Mediator-less microbial fuel cells do not require a mediator but uses electrochemically active bacteria to transfer electrons to the electrode (electrons are carried directly from the bacterial respiratory enzyme to the electrode)[8-9]. Some of the bacteria which have pili on their external membrane are able to transfer their electron production via these pili. Bacteria in mediator-less MFCs typically have electrochemically-active redox enzymes such as cytochromes on their outer membrane that can transfer electrons to external materials [1]

In the present study, mediator-less microbial fuel cells were used for electric current generation and simultaneous treatment of the wastewater. 


\section{MATERIAL AND METHODS}

\subsection{Wastewater Samples}

The domestic wastewater was collected from Naganahalli cross nala which is about $2 \mathrm{~km}$ away from the PDA college of Engg. Gulbarga and the dairy wastewater was collected from Gulbarga Milk Producer's Society Union Ltd, (Karnataka Milk Federation) Gulbarga which is about $5 \mathrm{~km}$ away from the college. Table 1 shows the characteristics of domestic and dairy wastewater. Both wastewater samples were kept in refrigerator at $4^{0} \mathrm{C}$ before use. The wastewaters were used as inoculum for all MFC tests without any modifications such as
$\mathrm{pH}$ adjustments or additions of nutrients etc. Experiments were conducted using full strength (100\%) wastewater, $75 \%$ wastewater and $50 \%$ wastewater.

Full strength wastewater: Plain wastewater sample without any dilution.

$75 \%$ wastewater: $100 \%$ wastewater diluted with $25 \%$ distilled water.

$50 \%$ wastewater: $100 \%$ wastewater diluted with $50 \%$ distilled water.

Table 1: Characteristics of domestic and dairy wastewater

\begin{tabular}{|c|c|c|c|c|}
\hline Sl.No & Characteristics & Unit & Domestic wastewater & Dairy Wastewater \\
\hline 1 & $\mathrm{pH}$ & - & 7.4 & 6.8 \\
\hline 2 & Colour & - & Greyish & Whitish \\
\hline 3 & Total Solids & $(\mathrm{mg} / \mathrm{L})$ & 1140 & 2856 \\
\hline 4 & Total Dissolved Solids & $(\mathrm{mg} / \mathrm{L})$ & 980 & 2074 \\
\hline 5 & Suspended Solids $(\mathrm{mg} / \mathrm{L})$ & 160 & 782 \\
\hline 6 & BOD $_{3} @ 27^{\circ} \mathrm{C}$ & $(\mathrm{mg} / \mathrm{L})$ & 290 & 654 \\
\hline 7 & COD & $(\mathrm{mg} / \mathrm{L})$ & 945 & 1868 \\
\hline 8 & Chlorides & $(\mathrm{mg} / \mathrm{L})$ & 262 & 232 \\
\hline
\end{tabular}

\subsection{MFC Fabrication}

Two MFC reactors were fabricated, one was single chamber MFC and the other was double chambered MFC. The reactors were fabricated using non-reactive plastic containers with total volume of 10 liters and the working volume was 8 liters. Graphite rods from pencils were used as both anode and cathode materials. The arrangement of graphite rods $(90 \mathrm{~mm}$ in length \& $2 \mathrm{~mm}$ in diameter) was made in such a way as to provide the maximum surface area for the development of biofilm on anode. The electrodes were connected using copper wire. The anode and the cathode chambers were separated by proton exchange membrane (agar salt bridge). The length and diameter of the agar salt bridge is 5 inches and 1.5 inches respectively. The electrodes were placed in the chambers, then were sealed, made airtight and were checked for water leakages.

Single chamber MFC: consists of single plastic container which is used as anode chamber. The agar salt bridge is joined to the anode chamber. The graphite rods are placed on the open end of the agar salt bridge which acts as cathode.

Double chamber MFC: consists of two plastic containers. One plastic container was used as anode chamber and the other as cathode chamber. The wastewater was fed to the anode chamber and KCL (catholyte) was fed to the cathode chamber. The anode and cathode chambers are connected using a agar salt bridge

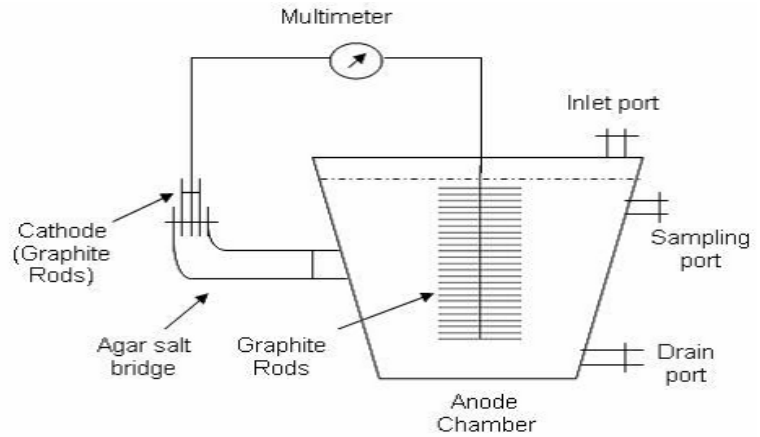

Fig 1: Single Chamber MFC

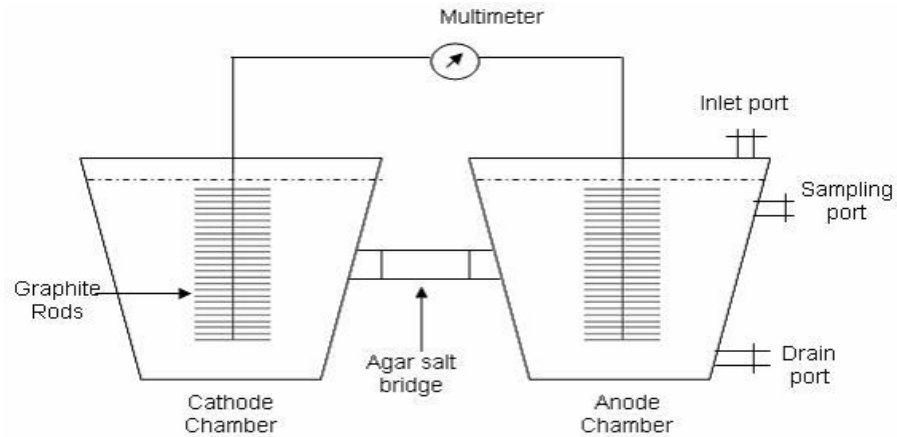

Fig 2: Double Chamber MFC 


\subsection{MFC Operation}

The study was conducted by feeding domestic wastewater and dairy wastewater separately to MFC-1 and MFC-2 with different strengths separately (i.e., 100\% strength without any dilution, $75 \%$ \& $50 \%$ strengths by diluting with distilled water $25 \% \& 50 \%$ respectively) for both the wastewaters. The anode chamber (anaerobic chamber) was filled with wastewater and the cathode chamber (aerobic chamber where oxygen was used as electron acceptor) was filled with KCL solution (catholyte). The internal wiring of anode and cathode was connected to a multimeter to complete the circuit. The entire setup was left for $1 \mathrm{hr}$ for stabilization and the reading in the multimeter was noted down every $24 \mathrm{hrs}$ for 12 days of operation.

\subsection{Monitoring of MFCs}

The current (I) in the MFC circuit was monitored at $24 \mathrm{hr}$ intervals using multimeter (Model No. DT830D). The samples were drawn from the chambers and analysed for the variation of wastewater characteristics. Analytical procedures followed were those outlined in Standard Methods for the examination of water and wastewater characteristics (1995).

\section{RESULTS AND DISCUSSIONS}

The single and double chambered MFC were run parallel. The MFCs were operated by feeding domestic and dairy wastewater with different wastewater concentrations separately. The effect of wastewater concentration on COD and TDS removal efficiency and current generation was observed.

\subsection{COD Removal Efficiency}

During operation, all MFCs were continuously monitored for waste (as COD) removal to enumerate the potential of fuel cell to act as wastewater treatment unit. Both domestic wastewater and dairy wastewater showed its potential for COD removal indicating the function of microbes, present in wastewaters in metabolizing the carbon source as electron donors. It is evident from experimental data that current generation and COD removal showed relative compatibility. Continuous COD removal was observed in both MFC-1 and MFC-2 during 12 days of operation. Initially full strength wastewater was used in the anodic chamber, and then it was replaced by $75 \%$ and $50 \%$ wastewater concentrations.

The effect of wastewater concentration on COD removal of domestic and dairy wastewater in MFC-1 and MFC-2 are shown in figure 3 to figure 6 . Experimental data indicated that COD removal efficiency was decreased with the decrease of wastewater concentration from $100 \%$ to $75 \%$ and $50 \%$ in both MFC-1 and MFC-2. The COD removal efficiency using domestic wastewater at $100 \%, 75 \%$ and $50 \%$ wastewater concentrations were $86.68 \%, 76.3 \%$ and $64.5 \%$ respectively in
MFC-1 and $88.4 \%, 78.6 \%$ and $67.2 \%$ respectively in MFC-2. The COD removal efficiency using dairy wastewater at $100 \%$, $75 \%$ and $50 \%$ wastewater concentrations were $84.8 \%, 77.8 \%$ and $72.1 \%$ respectively in MFC- 1 and $86.42 \%, 81.7 \%$ and $75.2 \%$ respectively in MFC-2. This relative slow COD removal was possibly due to less availability of biodegradable substrate in $75 \%$ and $50 \%$ wastewater samples than that of full strength wastewater leading to competitive inhibition in microorganisms.

The COD removal efficiency was almost same using full Strength dairy and domestic wastewater samples, but relatively slower COD removal was observed in $50 \%$ wastewater concentrations.

\subsection{Dissolved Solids Removal Efficiency}

Both MFC-1 and MFC-2 showed its potential for dissolved Solids removal. Initially full strength wastewater was used in the anodic chamber, and then it was replaced by $75 \%$ and $50 \%$ wastewater concentrations. The effect of wastewater concentration on dissolved solids removal of domestic and dairy wastewater in MFC-1 and MFC-2 are shown in figure 7 to figure 10. Experimental data indicated that dissolved removal efficiency was decreased with the decrease of wastewater concentration from $100 \%$ to $75 \%$ and $50 \%$ in both MFC-1 and MFC-2. The dissolved solids removal efficiency using domestic wastewater at $100 \%, 75 \%$ and $50 \%$ wastewater concentrations were $56.2 \%, 47.2 \%$ and $38.2 \%$ respectively in MFC-1 and 53.6\%, 45.8\% and 34.5\% respectively in MFC-2. The dissolved solids removal efficiency using dairy wastewater at $100 \%, 75 \%$ and $50 \%$ wastewater concentration were $57.68 \%, 52.7 \%$ and $46.5 \%$ respectively in MFC-1 and $55.44 \%, 49.72 \%$ and $45.5 \%$ respectively in MFC-2. This relative slow dissolved solids removal was possibly due to less availability of biodegradable substrate in $75 \%$ and $50 \%$ wastewater samples than that of full strength wastewater leading to competitive inhibition in microorganisms. The dissolved solids removal efficiency was almost same using full strength domestic and dairy wastewater samples, but relatively slower dissolved solids removal was observed in $75 \%$ and $50 \%$ wastewater concentrations 


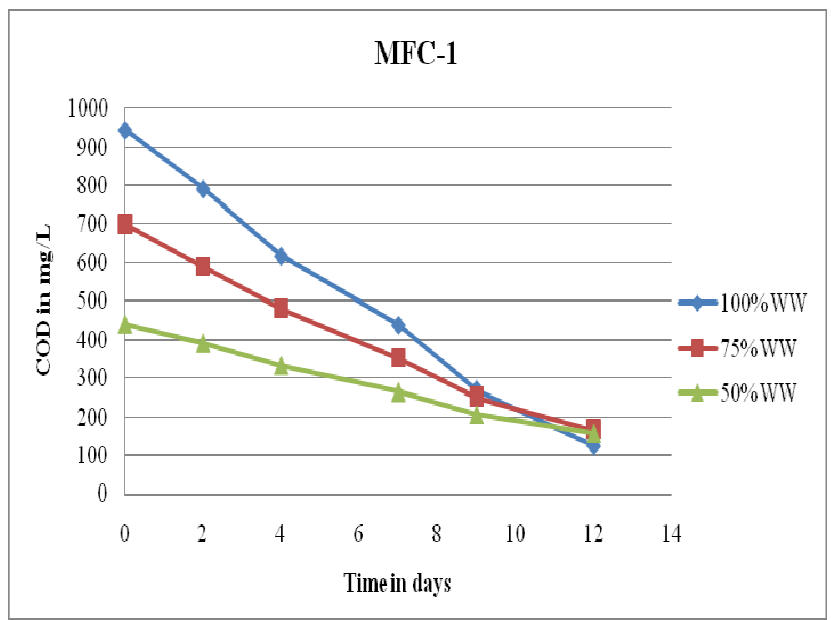

Fig.3. COD reduction in domestic wastewater at various concentrations in MFC-1

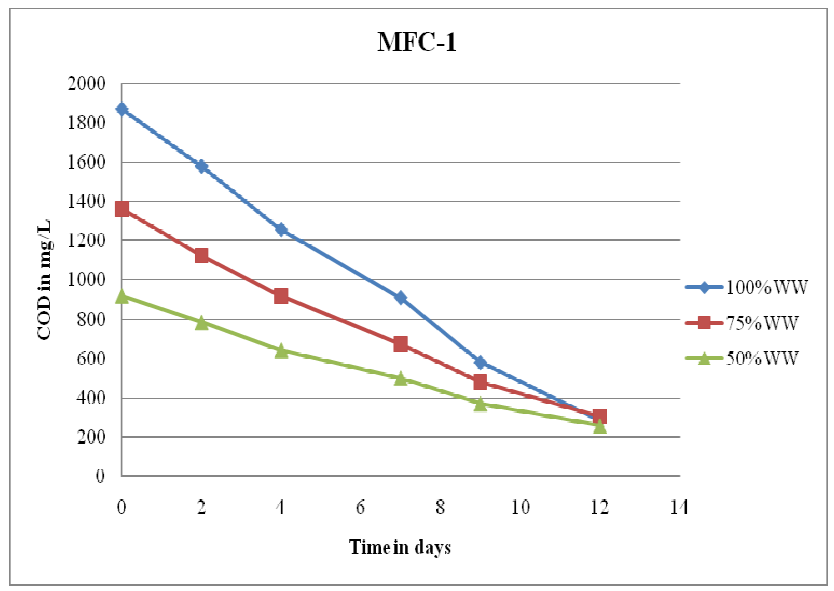

Fig.5. COD reduction in dairy wastewater at at various concentrations in MFC-1

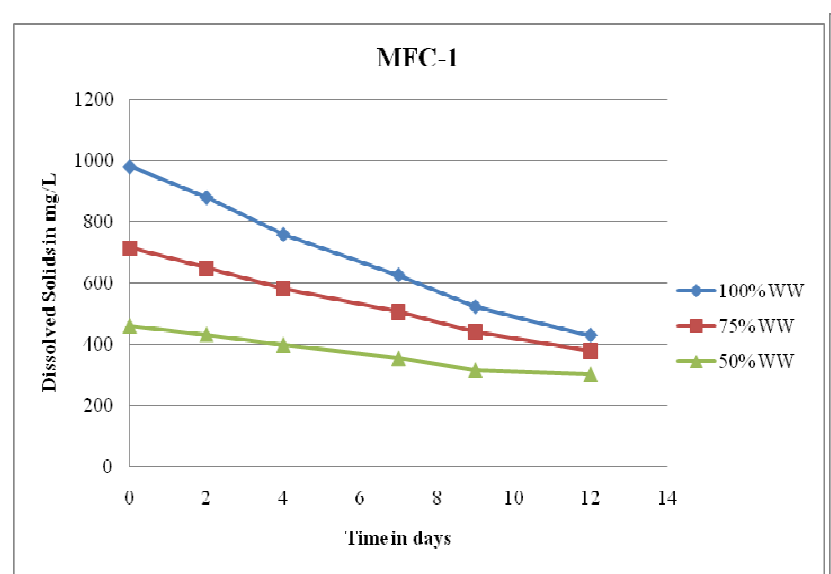

Fig.7. Dissolved Solids reduction in domestic wastewater at various concentrations in MFC-1

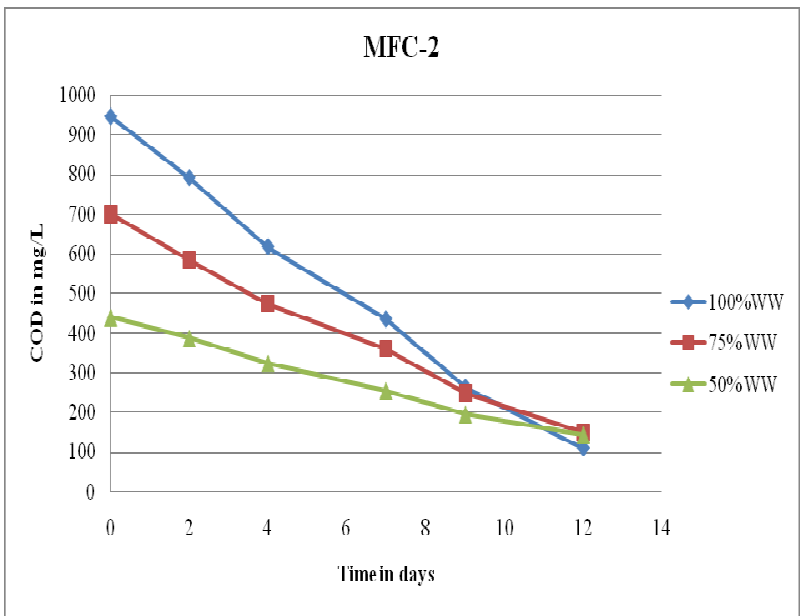

Fig. 4. COD reduction in domestic wastewater at various concentrations in MFC-2

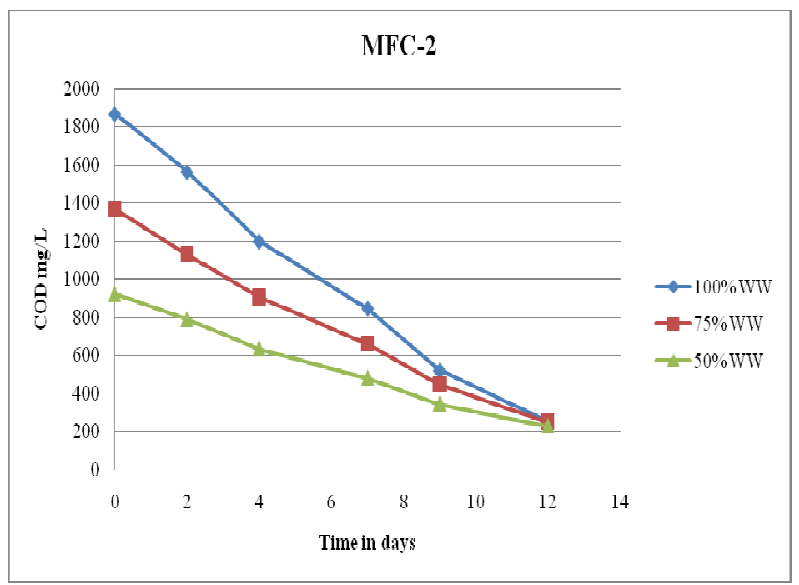

Fig. 6. COD reduction in dairy wastewater at various concentrations in MFC-2

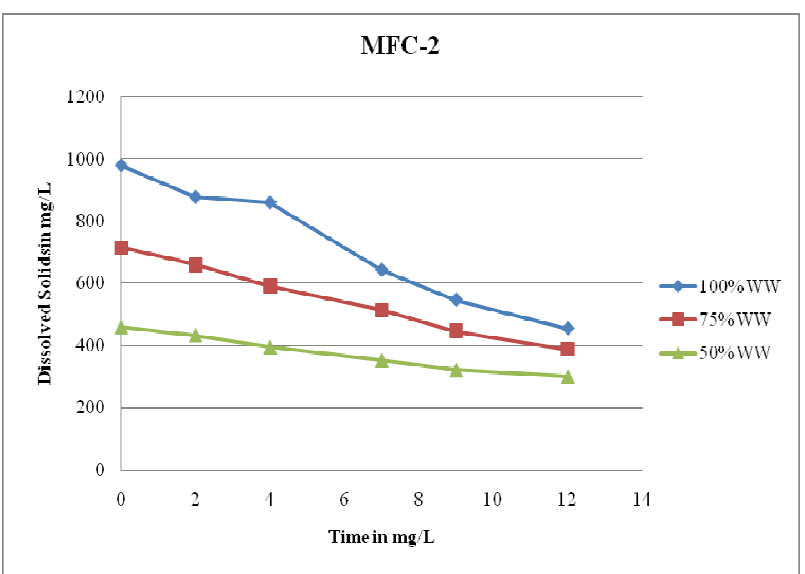

Fig. 8 Dissolved Solids reduction in domestic wastewater at various concentrations inMFC-2 


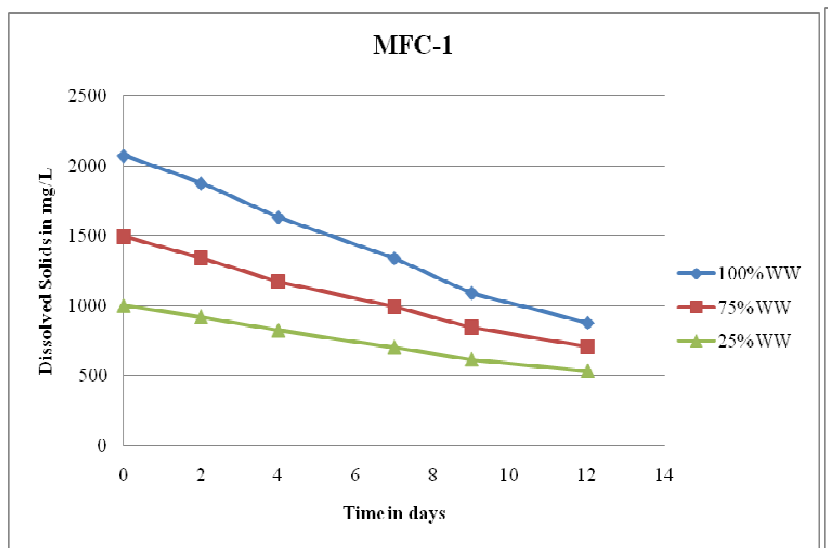

Fig.9. Dissolved Solids reduction in dairy Wastewater at various concentrations in MFC-1

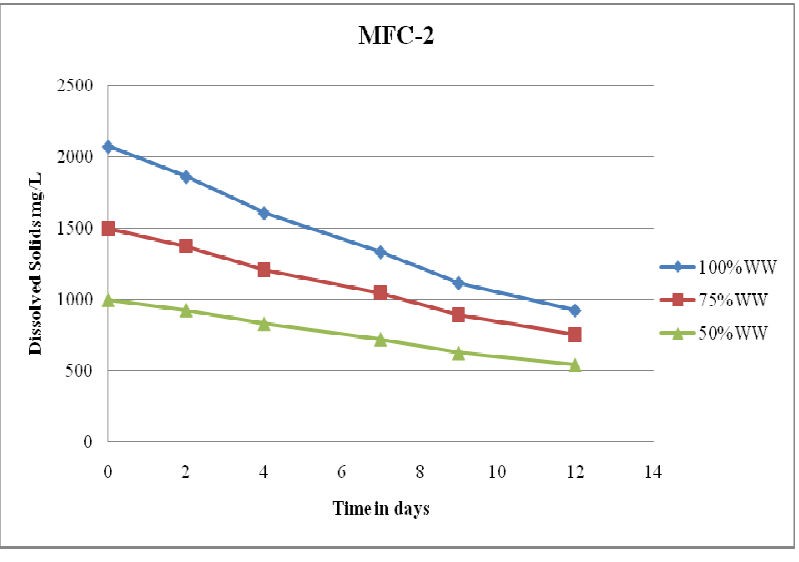

Fig. 10. Dissolved Solids reduction in dairy wastewater at various concentrations inMFC-2

Current Generation for Various Wastewater Concentrations in MFC-1 and MFC-2

Both MFC-1 and MFC-2 were operated with different wastewater samples at different conditions, as feed to support the formation of biomass and subsequent generation of electricity. The MFCs were continuously monitored during experiment and readings were taken after each $24 \mathrm{hr}$, inoculation time was considered as time 0 . The readings were noted down for 12 days of MFC operation. Preliminary experiments conducted using MFCs showed that electricity could be generated using different wastewaters. The current was measured for each concentration of both domestic and dairy wastewater separately. Initially full strength wastewater was used in the anodic chamber, and then it is replaced by $75 \%$ and $50 \%$ wastewater concentration. The current showed a gradual increase for few days, and then it was declined.

The effect of wastewater concentrations on current generation with the use of domestic and dairy wastewater in MFC-1 and MFC-2 are shown in figure 11 to figure 14. Experimental data indicated that current generation was decreased with the decrease of wastewater concentration from $100 \%$ to $75 \%$ and $50 \%$ in both MFC-1 and MFC-2. The maximum current obtained from domestic wastewater at $100 \%, 75 \%$ and $50 \%$ wastewater concentration are $0.84 \mathrm{~mA}, 0.69 \mathrm{~mA}$ and $0.5 \mathrm{~mA}$ respectively in MFC-1 and $0.56 \mathrm{~mA}, 0.4 \mathrm{~mA}, 0.28 \mathrm{~mA}$ respectively in MFC-2. The maximum current obtained from dairy wastewater at $100 \%, 75 \%$ and $50 \%$ wastewater concentration are $1.02 \mathrm{~mA}, 0.88 \mathrm{~mA}$ and $0.78 \mathrm{~mA}$ respectively in MFC-1 and $0.58 \mathrm{~mA}, 0.52 \mathrm{~mA}, 0.41 \mathrm{~mA}$ respectively in MFC-2. This variation in current generation is due to availability of less oxidizable substrates in $75 \%$ and $50 \%$ wastewater samples.

The current generation from dairy wastewater sample was higher than the domestic wastewater sample. The current generation was much higher in MFC-1 when compared with MFC-2. Logan et al., (2007) have reported the advantage of air- cathode MFC (compared with the cathode suspended in water) as oxygen transfer to the cathode occurs directly from air, and thus oxygen does not have to be dissolved in water. The abundant electron acceptor i.e., oxygen availability in air is the reason for the higher current generation.

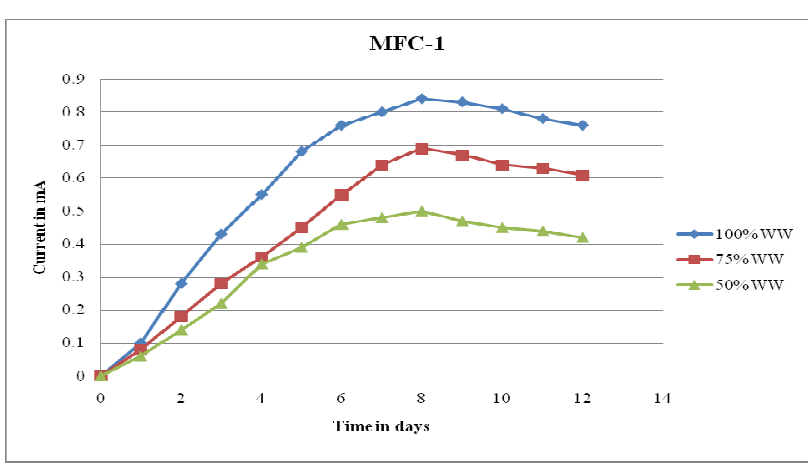

Fig.11 Current generation in domestic Wastewater at various concentrations in MFC-1

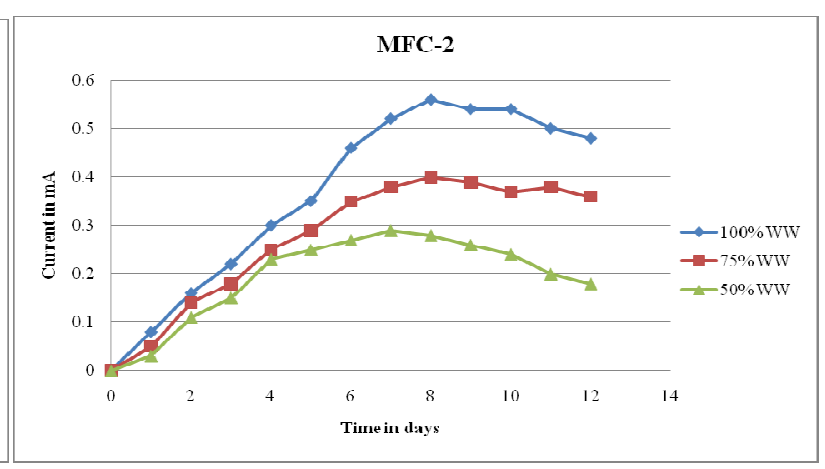

Fig. 12 Current generation in domestic wastewater at various concentrations inMFC-2 


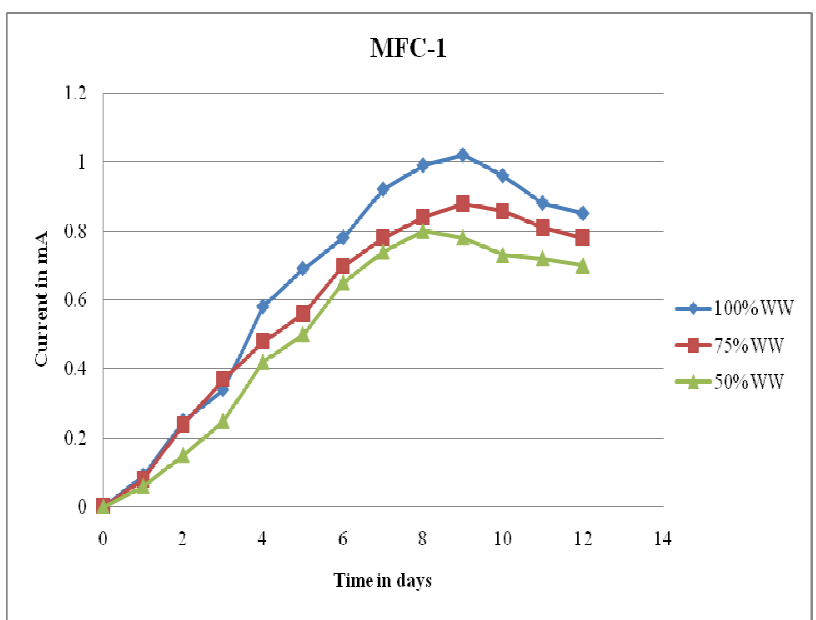

Fig.11 Current generation in dairy Wastewater at various concentrations in MFC-1

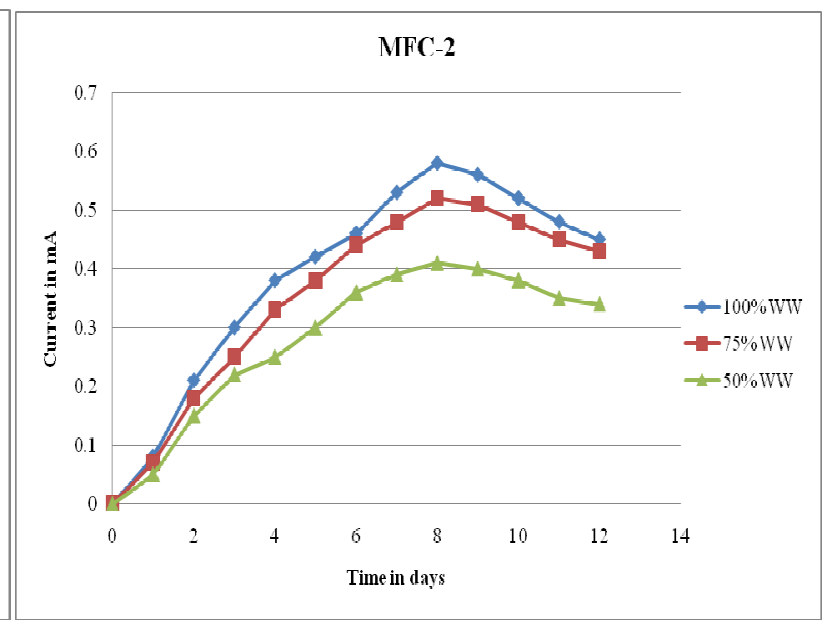

Fig. 12 Current generation in dairy wastewater at various concentrations inMFC-2

\section{CONCLUSIONS}

The study demonstrated that microbial fuel cell technology was able to treat domestic and dairy wastewater successfully, and microorganisms present in the wastewater are responsible for electricity generation and COD \& TDS removal. The single chamber air cathode MFC proves to be more reliable because of the reduced cost of construction, low maintenance and higher electricity generation when compared with double chambered MFC. The performance of MFCs decreased, with the decrease in the wastewater concentration. If electricity generation in these systems can be increased, MFC technology may provide a new method to offset wastewater treatment plant operating cost, making wastewater treatment more affordable for developing and developed nations. Thus, the combination of wastewater treatment along with electricity production may help in saving money as a cost of wastewater.

\section{REFERENCES}

[1] Muralidharan et al., "Impact of Salt Concentration on Electricity Production in Microbial Hydrogen Based Salt Bridge Fuel Cells, Indian Journal of Fundamental and Applied Life Sciences", Vol. 1 (2) April - June, pp. 178-184 (2011)

[2] Abhilasha S. M and Sharma V. N., " Bioelectricity production from various wastewaters through microbial fuel cell technology", Journal of Biochemical Technology, 2(1), pp.133-137 (2009)

[3] Kim BH, Ikeda T, Park HS et al, " Electrochemical activity of an $\mathrm{Fe}$ (III)-reducing bacterium, Shewanellaputrefaciens IR-1, in the presence of alternative electron acceptors", Biotech Tech 13. pp.475-478 (2002)

[4] Liu H., Ramnarayanan R. Logan B. E. "Production of electricity during wastewater treatment using a single chamber microbial fuel cell", Environmental Science and Technology, 38, pp. 2281-2285 (2004)

[5] Logan B. E and Regan J. M, "Microbial fuel cells challenges and applications, Environmental Science and Technology", 40, pp 5172-5180 (2006)

[6] Rabaey K, Boon N, SicilianoSD, Verhaege M and Verstraete W, "Biofuel cells select for microbial consortia that self-mediate electron transfer", Applied and Environmental Microbiology 70. pp.5373-5382 (2004)

[7] Park DH and Zeikus JG, "Electricity generation in microbial fuel cells using neutral red as an electronophore", Applied Environmental Microbiology 66.pp.1292-1297 (2000).

[8] Bond DR, Lovley DR, "Electricity production by Geobacter sulfurreducens attached to electrodes", Applied Environmental Microbiology, 69(3) pp.15481555 (2003).

[9] Chaudhuri SK and Lovley DR. "Electricity generation by direct oxidation of glucose in mediatorless microbial fuel cells", Nature Biotechnology 21 pp.1229-1232 (2003).

[10] Standard Methods for Examination of Water and Wastewater, $19^{\text {th }}$ Edition. Prepared and Published by American Public Health Association,American Water Works Association, Water Pollution Control Federation (1995) 